\title{
Sm-Nd картирование и тектоническое районирование Бунделкханского кратона Индийского щита
}

\author{
Нестерова Н.С. ${ }^{1}$, Баянова Т.Б. ${ }^{2}$, Сингх В.К. ${ }^{3}$, Светов С.А. ${ }^{1}$, Слабунов А.И. ${ }^{1}$ \\ ${ }^{1}$ Институт геологии КарНЦ РАН, Петрозаводск, пеst345@gmail.com \\ ${ }^{2}$ Геологический институт КНЦ РАН, Апатить \\ ${ }^{3}$ Бунделкхандский университет, геологический ф-т, Джанси, Индия
}

Аннотация. Sm-Nd систематика неоархейских гранитов Бунделкханского кратона Индийского щита позволяет установить три существенно различающиеся по значениям модельных Sm-Nd возрастав части. Выделяются Северно- и Южно- Бунделкханские блоки (террейны) с палео-мезоархейскими модельными возрастами (от 3029 до 4017 млн. лет) и отрицательными значениями $\mathrm{Nd}(\mathrm{T})$ (до -13.82). Эти блоки разделены сутурой (или Центрально-Бунделкханским террейном), в котором отмечаются как метки древнего мезо- и палеоархейского вещества так и более молодого неоархейского с положительными значениями $\varepsilon \mathrm{Nd}(\mathrm{T})($ до +3.87$)$. Результаты Sm-Nd картирования кратона хорошо сопоставляются с тектоническим районированием, выполненным на основе анализа геологических и геофизических материалов.

Ключевые слова: $\mathrm{Sm}-\mathrm{Nd}$, $\varepsilon \mathrm{Nd}$, Бунделкханский кратон, архей, тектоническое районирование.

\section{Sm-Nd mapping and tectonic division of the Bundelkhand Craton in the Indian Shield}

\author{
Nesterova N.S. ${ }^{1}$, Bayanova T.B. ${ }^{2}$, Singh V.K. ${ }^{3}$, Svetov S.A. ${ }^{1}$, Slabunov A.I. ${ }^{1}$ \\ ${ }^{1}$ Institute of Geology, Karelian RC, RAS, Petrozavodsk,nest345@gmail.com \\ ${ }^{2}$ Geological institute KSC RAS, Apatity \\ ${ }^{3}$ Department of Geology, Institute of Earth Sciences, Bundelkhand University, Jhansi, India
}

\begin{abstract}
Three units, differing markedly in Sm-Nd model age values, are distinguished based on the $\mathrm{Sm}-\mathrm{Nd}$ systematics of Neoarchean granites in the Bundelkhand Craton, Indian Shield. The North and South Bundelkhand blocks (terrains) with Paleo-Mesoarchean model ages of 3029 to $4017 \mathrm{Ma}$ and negative $\varepsilon N d(\mathrm{~T})$ values of up to -13.82 are distinguished. The blocks are separated by a suture (the Central Bundelkhand terrain), in which labels of old Meso- and Paleoarchean substance and younger Neoarchean substance with positive $\varepsilon N d(T)$ values of up to +3.87 occur. The results of the Sm-Nd mapping of the craton are clearly correlated with tectonic division based on analysis of geological and geophysical data.
\end{abstract}

Key words: Sm-Nd, $\boldsymbol{\varepsilon} \mathrm{Nd}$, Bundelkhand Craton, Archean, tectonic division.

\section{Введение}

Бунделкхандский кратон состоит на 80-90 \% из неоархейских микроклиновых гранитов (Ramakrishnan, Vaidyanadhan, 2010) и ранее рассматривался как гранитный массив. Вместе с тем, здесь развиты палео- и неоархейские (3.6-3.2 и 2.67 млрд. лет) гранитоиды тоналит-трондьемитгранодиторитовой (ТТГ) ассоциации (Mondal et al., 2002; Verma et al., 2016, Kaur et al., 2016), неоархейские (2.54-2.52 млрд. лет) санукитоиды (Joshi, Slabunov, 2019), архейские расслоенные интрузии (Slabunov et al., 2018) а также зеленокаменные комплексы (Singh, Slabunov, 2015; Slabunov, Singh, 2018 и ссылки там). Архейские комплексы секутся несколькими генерациями протерозойских даек (Pradhan et al., 2012) и гигантских кварцевых жил (Pati et al., 2007; Слабунов и др., 2017).

В условиях резкого преобладания в пределах всего кратона неоархейских гранитов геологические методы не позволяют оценить роль и распределение в пространстве древней (палеомезоархейской, прежде всего) коры в его структуре, а значит, и провести тектоническое районирование. Вместе с тем эта задача может быть решена при использовании $\mathrm{Sm}-\mathrm{Nd}$ картирования (Champion, 2013; Mole et al., 2015; Schoene et al., 2009). 


\section{Sm-Nd систематика неоархейских гранитов}

Для оценки роли древнего и более молодого вещества в составе коры Бунделкханского кратона по всей площади была отобрана серия проб (рис. 1) из микроклиновых неоархейских (2.51-2.53 млрд. лет) гранитов (Singh et al., 2019), которые широко распространены здесь и несколько проб из более древних ТТГ. Всего было исследовано 27 образцов гранитоидов: 10 - из СеверноБунделкханского террейна, 7 - из Южно-Бунделкханского и 10 - из Центрально-Бунделкханского.

$\mathrm{Sm}-\mathrm{Nd}$-модельные возрасты гранитов Бунделкханского кратона вычисленные относительно «деплетированного» резервуара DM с использованием двухстадийной модели находятся в пределах от 2576 до 4017 млн. лет (рис. 1, 2). Значения $\varepsilon \mathrm{Nd}(\mathrm{T})(\varepsilon \mathrm{Nd}$ во время кристаллизации) гранитов кратона варьируют от +3.15 до -13.82 .

В Южно-Бунделкханском террейне модельные $\mathrm{Sm}-\mathrm{Nd}$ возрасты оцениваются 3073-4017 млн. лет, величины $\varepsilon \mathrm{Nd}(\mathrm{T})$ отрицательные и укладываются в интервал от -2.22 до -13.82. В Северно-Бунделкханском террейне модельные возрасты гранитов также несут древние метки $\mathrm{T}\left(\mathrm{Nd}_{\mathrm{DM} 2}\right)=3170-3521$ млн. лет, значения $\varepsilon \mathrm{Nd}(\mathrm{T})$ варьируют от -2.84 до -7.71. Образование гранитои-

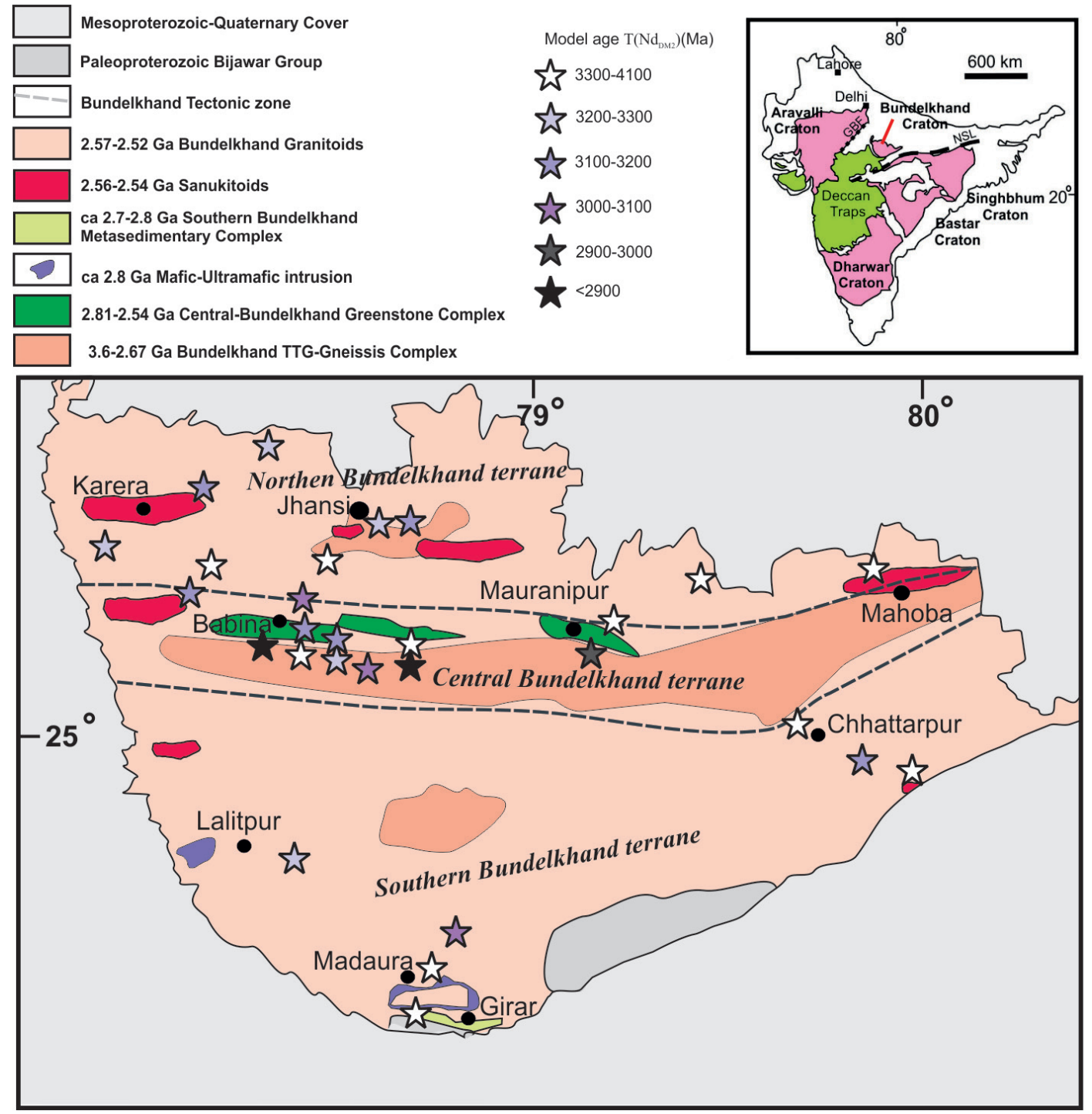

Рис. 1. Распределение значений Sm-Nd модельных возрастов гранитоидов на схеме тектонического районирования Бунделкхандского кратона (Joshi, Slabunov, 2019; Slabunov, Singh, 2019 с изменениями).

Fig. 1. Sample locations and model Sm-Nd ages on a map showing the tectonic division of the Bundelkhand Craton (Joshi \& Slabunov, 2019; Slabunov \& Singh, 2019, revised). 


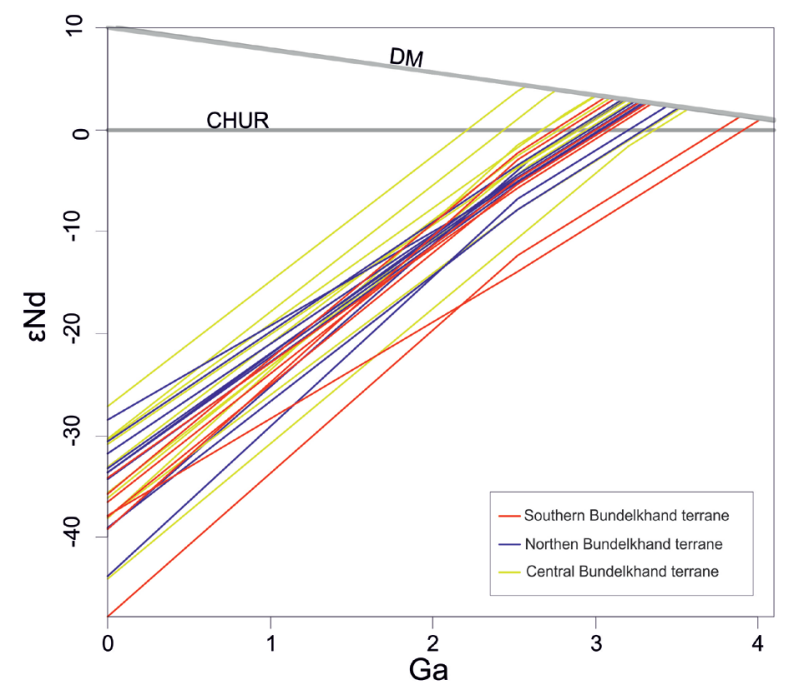

Рис. 2. Модельные возрасты $\mathrm{T}\left(\mathrm{Nd}_{\mathrm{DM} 2}\right)$ гранитов Бунделкхандского кратона.

Fig. 2. Model $\mathrm{T}\left(\mathrm{Nd}_{\mathrm{DM} 2}\right)$ ages of granites from the Bundelkhand Craton.

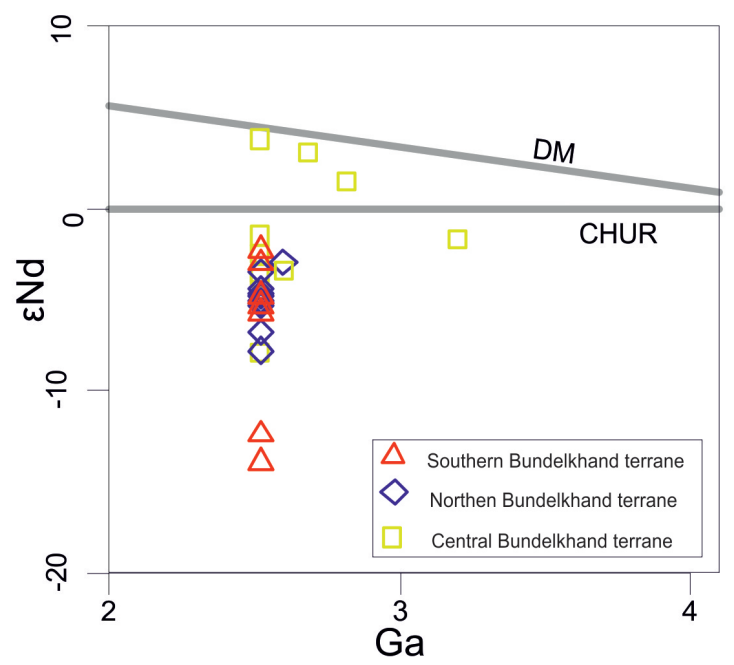

Рис. 3. Sm-Nd изотопные данные $(\varepsilon \mathrm{Nd})$ гранитов Бунделкхандского кратона.

Fig. 3. Sm-Nd isotope data (as $\varepsilon N d$ ) of granites from the Bundelkhand Craton.

дов Северно- и Южно- Бунделкханских террейнов происходило, вероятно, за счет плавления более древней коры кратона с минимальным привносом более молодого вещества.

В Центрально-Бунделкханском террейне наблюдается несколько иная картина, здесь отмечаются наиболее молодые модельные возрасты гранитов и положительные значения $\varepsilon \mathrm{Nd}(\mathrm{T})$, что свидетельствует о существенном вкладе ювинильного вещества. Вместе с тем присутствуют и древние модельные $\mathrm{Sm}-\mathrm{Nd}$ возрасты (рис. 3). Модельный возраст гранитоидов центрального террейна изменяется от 2576 до 3572 млн. лет, $\varepsilon \mathrm{Nd}(\mathrm{T})$ колеблется от +3.15 до -7.84. Данный террейн представляет собой сутуру, с широчайшими вариациями модельных возрастов гранитоидов, которая разделяет блоки (террейны), сложенные гранитоидами с древними (палео-мезоархейскими) модельными возрастами.

\section{Главные выводы}

По результатам Sm-Nd картирования Бунделкхандского кратона установлено три существенно различающихся по значениям модельных Sm-Nd возрастов части. Выделяются Северно- и Южно- Бунделкханские блоки (террейны) с древними модельными возрастами (от 3029 до 4017 млн. лет) и отрицательными значениями $\varepsilon \mathrm{Nd}(\mathrm{T})$ (до -13.82). Эти блоки разделены сутурой (Центрально-Бунделкханским террейном), в которой отмечаются как метки древнего мезо- и палеоархейского вещества так и более молодого неоархейского с положительными значениями $\varepsilon \mathrm{Nd}(\mathrm{T})$ (до +3.87). Полученные данные хорошо согласуются с геологическими и геофизическими данными (Slabunov, Singh, 2019).

Работа выполнена при финансовой поддержке РФФИ (грант 17-55-45005 ИНД-а), является вкладом в выполнение государственного задания КарНЦ РАН (ИГ КарНЦ РАН, проект A18-118020290085-4).

\section{Литература}

1. Слабунов А.И., Синг В.К., Щипцов В.В., Лепехина Е.Н., Кевлич В.В. Новое палеопротерозойское (1.9-1.8 млрд. лет) событие эволюции земной коры Бунделкхандского кратона (Индия): результаты датирования цирконов (SHRIMP) из гигантских кварцевых жил // Геодинамика раннего докембрия: сходства и различия с фанерозоем. Материалы конференции и путеводитель экскурсий. Петрозаводск: КарНЦ PAH. 2017. C. 239-241. 
2. Champion D.C. Neodymium Depleted Mantle Model Age Map of Australia: Explanatory Notes and User Guide (Record 2013/44 edition). Geoscience Australia. 2013. 209 p.

3. Joshi K.B., Slabunov A. Neoarchean sanukitoids from the Karelian and Bundelkhand cratons: comparison of composition, regional distribution and geodynamic setting. Transactions of KarRC. RAS. 2019. V. 2. P. 1-21. DOI: $10.17076 /$ geo841.

4. Kaur P., Zeh A., Chaudhri N., Eliyas N. Unravellingthe record of archaean crustal evolution of the Bundelkhand Craton, northern India using U-Pb zircon Monazite ages, Lu-Hf isotope systematics, and whole-rock geochemistry of granitoids: Precambrian Research. 2016. V. 281. P. 384-413. doi:10.1016/j.precamres.2016.06.005.

5. Mole D.R., Fiorentini M.L., Cassidy K.F., Thebaud N., McCuaig T.C., Doublier M.P., Duuring P., Romano S.S., Maas R., Belousova E.A., Barnes S.J., Miller J. Crustal evolution, intra-cratonic architecture and the metallogeny of an Archaean craton. Geological Society. London. 2015. V. 393. P. 23-80. Special Publications.

6. Mondal M.E.A., Goswami J.N., Deomurari M.P., Sharma K.K. Ion microprobe $207 \mathrm{~Pb} / 206 \mathrm{~Pb}$ ages of zircon from the Bundelkhand massif, northern India: Implication for crustal evolution of Bundelkhand - Aravalli protocontinent: Precambrian Research. 2002. V. 117. P. 85-100. doi:10.1016/S0301-9268(02)00078-5.

7. Pati J.K., Patel S.C., Pruseth K.L., Malviya V.P., Arima M., Raju S., Pati P., Prakash K. Geology and geochemistry of giant quartz veins from the Bundelkhand Craton, Central India and their implications: Journal of Earth System Science. 2007. V. 116. P. 497-510. doi:10.1007/s12040-007-0046-y.

8. Pradhan V.R., Meert J.G., Pandi M.K., Kamenov G., Mondal, M.E.A. Paleomagnetic and geochronological studies of the mafic dyke swarms of Bundelkhand Craton, Central India: Implications for the tectonic evolution and paleogeographic reconstructions: Precambrian Research. 2012. V. 198-199. P. 51-76. doi:10.1016/j.precamres.2011.11.011.

9. Ramakrishnan M., Vaidyanadhan R. Geology of India. V. 1: Geol. Soc. of India. 2010. 556 p.

10. Schoene B., Dudas F.O.L., Bowring S.A., Wit M. Sm-Nd isotopic mapping of lithospheric growth and stabilization in the eastern Kaapvaal craton // Terra Nova. 2009. V. 21. 3. P. 219-228. doi: 10.1111/j.1365-3121.2009.00877.x

11. Singh P.K., Verma S.K., Singh V.K., Moreno J.A., Oliveira E.P., Mehta P. Geochemistry and petrogenesis of sanukitoids and high-K anatectic granites from the Bundelkhand craton: Implications for the late-Archean crustal evolution // Journal of Asian Earth Sciences. 2019. https://doi.org/10.1016/j.jseaes.2018.12.01.

12. Singh V.K., Slabunov A. The Central Bundelkhand Archaean greenstone complex, Bundelkhand Craton, Central India: Geology, composition, and geochronology of supracrustal rocks: International Geology Review. 2015. V. 57. V. 11-12. P. 1349-1364. doi:10.1080/00206814.2014.919613.

13. Slabunov A., Egorova S., Singh V. K., Svetov S., Kumar S. Archean mafic-ultramafic Ikauna layered intrusion, Bundelkhand craton, India: petrography and geochemistry // Arch \& Anthropol Open Acc. 3 (suppl-2). 2018. P. 49-55. DOI: 10.31031/AAOA.2018.03.000557.

14. Slabunov A., Singh V.K. Meso-Neoarchaean crustal evolution of the Bundelkhand Craton, Indian Shield: new data from greenstone belts. International Geology Review. 2018. DOI: 10.1080/00206814.2018.1512906.

15. Slabunov A., Singh V.K. The new tectonic division of the Bundelkhand Craton Indian Shield // Труды Ферсмановской научной сессии ГИ КНЦ РАН. 2019.

16. Verma S.K., Verma S.P., Oliveira E.P., Singh V.K., Moreno J.A. LA-SF-ICP-MS zircon U-Pb geochronology of granitic rocks from the central Bundelkhand greenstone complex, Bundelkhand craton, India // Journal of Asian Earth Sciences. 2016. V. 118. P. 125-137. 